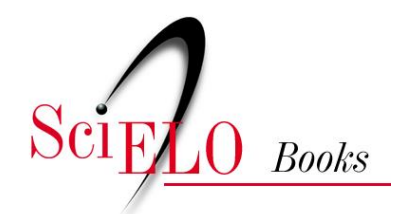

\title{
1 - A tecnologia social e seus desafios
}

\author{
Renato Dagnino
}

\section{SciELO Books / SciELO Livros / SciELO Libros}

DAGNINO, R. A tecnologia social e seus desafios. In: Tecnologia Social: contribuições conceituais e metodológicas [online]. Campina Grande: EDUEPB, 2014, pp. 19-34. ISBN 978-85-7879-327-2.

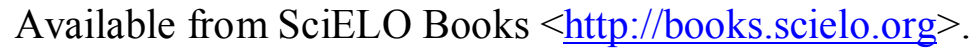

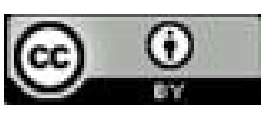

All the contents of this work, except where otherwise noted, is licensed under a Creative Commons Attribution $\underline{4.0 \text { International license. }}$

Todo o conteúdo deste trabalho, exceto quando houver ressalva, é publicado sob a licença Creative Commons Atribição 4.0.

Todo el contenido de esta obra, excepto donde se indique lo contrario, está bajo licencia de la licencia $\underline{\text { Creative }}$ Commons Reconocimento 4.0. 


\section{1}

\section{A tecnologia social e seus desafios}

Este capítulo ${ }^{1}$ explora o processo recente, e em certo sentido único, que se expande rapidamente no Brasil, de conceber tecnologias para a inclusão social (IS). Seu enfoque, interdisciplinar, orientado por problema e para a elaboração de políticas, como convém ao tema, é balizado pelo campo dos Estudos Sociais da Ciência e da Tecnologia (ESCT). Inicia-se com uma pergunta: por que é necessário conceber tecnologia social (TS)?

Essa pergunta inicial pode ser preliminarmente respondida pela menção a duas razões. Primeiro, porque se considera que a tecnologia convencional (TC), a tecnologia que hoje existe, que a empresa privada utiliza, não é adequada para a IS. Ou seja, existem aspectos na TC, crescentemente eficientes para os propósitos de maximização do lucro privado para os quais é desenvolvida nas empresas, que limitam sua eficácia para a IS. Segundo, porque se percebe que as instituições públicas envolvidas com a geração de conhecimento científico e tecnológico (universidades, centros de pesquisa etc.) não parecem estar ainda plenamente capacitadas para desenvolver uma tecnologia capaz de viabilizar a IS e tornar autossustentáveis os empreendimentos autogestionários que ela deverá alavancar. Isso torna necessário um processo de sensibilização dessas organizações e de outras, situadas em diferentes partes do aparelho de Estado e da sociedade em geral, a respeito do tema. Tal sensibilização se inicia por um processo de reflexão como o aqui proposto.

Para guiar esse processo, vou tomar essas duas partes da resposta como hipóteses, concentrando-me em cinco pontos:

1. Como é a TC, a tecnologia que utilizam as empresas privadas?

2. Que tecnologias demandam a IS e os empreendimentos autogestionários? Ou, em outras palavras, como é a TS (denominação que darei a priori, sem conceituar, previamente, a essa tecnologia)?

1 Texto originalmente publicado no livro Tecnologia social: uma estratégia para o desenvolvimento (2004). 
3. O que faz a TC ser diferente da TS? O que diferencia a tecnologia que existe daquela que seria necessária para tornar viável a IS e os empreendimentos autogestionários?

4. Será que as instituições públicas que produzem conhecimento (a universidade, em particular) podem aproximar essas duas tecnologias? Será que a universidade pode, a partir da TC com a qual está "acostumada", gerar a TS necessária a esses empreendimentos?

5. Como começar a fazer com que a universidade possa, de fato, engajar-se numa empreitada tão difícil, tão ampla, mas tão necessária para o Brasil e para outros países?

A seguir, para fixar ideias e guiar o leitor, e tal como farei ao longo deste capítulo, apresento uma síntese do que estou expondo.

\section{Como é a TC?}

- Mais poupadora de mão de obra;

- Mais intensiva em insumos sintéticos do que seria conveniente;

- Possui escalas ótimas de produção sempre crescentes;

- Sua cadência de produção é dada pelas máquinas;

- Ambientalmente insustentável;

- Possui controles coercitivos que diminuem a produtividade.

Sobre a primeira questão - como é a TC? - eu diria que ela é mais poupadora de mão de obra do que seria conveniente. A história da tecnologia, a história da produção do conhecimento, mostra uma trajetória de economia do trabalho humano. Se isso é inerente à maneira de o homem trabalhar, de se relacionar com a natureza, ou se é algo específico de um momento ou um estágio de sua passagem sobre o planeta, não vem agora ao caso. Mas até que ponto essa tecnologia capitalista, a TC, poupa trabalho humano mais do que seria conveniente é uma questão a ser trabalhada, a ser pensada. O que posso dizer, preliminarmente, é que ela é mais poupadora de mão de obra do que seria conveniente porque o lucro das empresas depende de uma constante redução da mão de obra incorporada ao produto, ou do tempo de trabalho socialmente necessário para produzir mercadorias.

A TC maximiza a produtividade em relação à mão de obra ocupada. $\mathrm{Na}$ realidade, o indicador de produtividade que correntemente se utiliza é enviesado, não é um indicador neutro. 
Ele implica que se esteja sempre considerando mais produtiva uma empresa que diminui o denominador da fração produção por mão de obra ocupada. Assim, por exemplo, se uma empresa consegue diminuir a mão de obra numa proporção maior do que diminuiu sua produção, ela se torna mais "produtiva". Não importa se o que fez foi "enxugar" o pessoal mediante uma reorganização do processo de trabalho que possibilita que um mesmo trabalhador tenha de desempenhar uma tarefa antes realizada por dois. Quando o indicador de produtividade é estimado em termos monetários, revela-se ainda mais enviesado. Nesse caso, cada vez que uma empresa consegue diminuir o valor de sua folha de pagamento (por exemplo, despedindo trabalhadores com mais "tempo de casa" e contratando para a mesma função outros mais jovens), torna-se mais "produtiva". Isso mostra que os próprios indicadores que vamos utilizar para avaliar tecnologias autogestionárias terão de ser bem diferentes.

\section{Como é a TC?}

- Segmentada: não permite controle do produtor direto;

- Maximiza a produtividade em relação à mão de obra ocupada;

- Alienante: não utiliza a potencialidade do produtor direto;

- Possui padrões orientados pelo mercado externo de alta renda;

- Hierarquizada: demanda a figura do chefe etc;

- Monopolizada pelas grandes empresas dos países ricos.

Diria também que ela possui escalas ótimas de produção sempre crescentes. Ou seja, a cada nova vindima (safra) tecnológica, a cada nova onda tecnológica ou a cada novo conjunto de inovações, as tecnologias produzidas têm escala cada vez maior. Ou seja, a escala de produção ótima é crescente. Trocando em miúdos, se você quer instalar hoje uma fábrica de automóveis turn key ("chave na mão") no estado da arte para produzir cinco unidades por semana, não irá encontrar. Essa fábrica existia no começo do século XX; no começo do século XXI não existe mais. Ou, se existe, não é mais a que se poderia considerar como estando no estado da arte. De tal forma que um pequeno capitalista, um pequeno empresário, estará sempre em desvantagem em relação àquele com recursos suficientes para adquirir a última tecnologia. Ele terá de se contentar em utilizar uma tecnologia que não é a mais eficiente segundo os parâmetros capitalistas. Isso gera um grande problema praticamente insolúvel, dentro 
dos marcos da TC, para o pequeno empresário capitalista. A utilização da TC implica uma condição de desvantagem inerente para o pequeno produtor e é quase um impedimento para a sustentabilidade (ou, usando o jargão da moda, competitividade) do empreendimento - quase por definição, pequeno - autogestionário.

Além disso, ela é ambientalmente insustentável, porque o capitalismo não considera a deterioração do meio ambiente como custo, como vocês sabem, em sua contabilidade. A forma como se concebe ou projeta a tecnologia no capitalismo não leva em conta uma série de parâmetros. Não é só o meio ambiente que é reputado uma "externalidade". Obrigar o trabalhador a fazer, durante trinta anos, uma tarefa repetitiva e insalubre, condenar milhões de pessoas (2 milhões só em São Paulo) ao desemprego, como não "custa" nada, não pode ser internalizado no cálculo técnico-econômico que as empresas usam para desenvolver tecnologia.

A TC é intensiva em insumos sintéticos produzidos por grandes empresas, o que, além de ambientalmente problemático, leva a uma dependência muito grande do pequeno produtor. Sua cadência de produção é dada pela máquina, e não pelo trabalhador. Ela possui controles coercitivos que diminuem sua produtividade. A resistência da classe operária (ou o que o patrão chamaria de boicote operário) é algo natural, compreensível e que sempre existiu. Um operário que está sendo explorado numa empresa, num processo de trabalho que o penaliza, vai tentar boicotar a produção. Por isso, a tecnologia capitalista tem de incorporar controles coercitivos para evitar que esse boicote possa ser efetivado, e isso implica um custo de produção maior do que o que ocorreria se ela fosse adequada para a produção autogestionária.

A TC é também segmentada: não porque, ao sê-la, se torne mais eficiente ou "produtiva", e sim porque, ao não permitir o controle do produtor direto sobre o processo de trabalho, torna sempre necessário um patrão, um capitalista, um chefe, um capataz, ou, mais modernamente, um engenheiro. Só ele detém o controle sobre a totalidade dos processos de produção, de manutenção, de concepção. Seus segmentos podem ser operados e parcialmente controlados por conjuntos de trabalhadores. Eles, entretanto, jamais conhecerão outros componentes desses processos.

Ela é também alienante, pois não utiliza a potencialidade do produtor direto. Mas a criatividade, a potencialidade do produtor direto que a TC inibe pode ser liberada no interior de um empreendimento autogestionário. 
As características da TC são determinadas pelos mercados de alta renda dos países avançados. O novo conhecimento produzido nesses países, responsáveis por mais de $95 \%$ do que se gasta em pesquisa no mundo, está sempre plasmado, materializado, nas tecnologias que satisfazem o consumo de alta renda. A tecnologia que satisfaz as demandas das classes ricas, dos países ricos é mais moderna - a hitec.

A hitec é monopolizada pelas grandes empresas dos países ricos. As vinte empresas que mais gastam em pesquisa, no mundo, gastam mais do que dois países, que não são Bangladesh e Paraguai, são França e GrãBretanha. Essa comparação, o fato que de um lado temos vinte empresas e de outro, dois países que são líderes em muitas áreas do conhecimento, nos dá uma ideia de quão monopolizada está a produção de ciência e tecnologia $(\mathrm{C} \& \mathrm{~T})$. E consequentemente quão absurda é a ideia de que a tecnologia é neutra.

As tecnologias que satisfazem o consumo popular, a satisfação de necessidades básicas, as que servem para produzir a infraestrutura, ou para a agregação de valor às matérias-primas dos países de Terceiro Mundo, essas tecnologias estão paradas no tempo. Há muito, elas não se renovam por novo conhecimento.

\section{Como é, ou como deveria ser a TS?}

Embora as características da TS já tenham sido, por exclusão ou por negação, enunciadas ao se criticar a TC, é conveniente adicionar alguns elementos.

Como é (ou deveria ser) a TS?

- Adaptada a pequeno tamanho;

- Liberadora do potencial físico e financeiro; e da criatividade do produtor direto;

- Não discriminatória (patrão $\times$ empregado);

- Capaz de viabilizar economicamente os empreendimentos autogestionários e as pequenas empresas;

- Orientada para o mercado interno de massa ${ }^{2}$;

- Ela deve ser adaptada ao reduzido tamanho físico e financeiro; não discriminatória; liberada da diferenciação - disfuncional, anacrônica e prejudicial nos ambientes autogestionários - entre

2 Faço um tratamento detalhado do tema em Dagnino (2004, p. 103-146). 
patrão e empregado; orientada para um mercado interno de massa; libertadora do potencial e da criatividade do produtor direto. Resumindo, deve ser capaz de viabilizar economicamente os empreendimentos autogestionários.

E, finalmente, uma questão que vai ser retomada ao longo deste capítulo: se o empreendimento autogestionário não for competitivo (ou não tiver sustentabilidade) em relação ao grande capital, não vai conseguir constituir uma alternativa econômica, nem chegar a ser uma alternativa real de IS para a população marginalizada.

\section{O que faz a TC ser diferente da TS?}

A TC é funcional para a empresa privada, que no capitalismo é a responsável pela produção de bens e serviços para a população. Isso, apesar de óbvio, merece ser salientado em função do enorme impulso feito pelos governos dos países avançados e pelas suas grandes empresas, no sentido de fazer com que essa tecnologia seja vista não só como a melhor, como a última, como a de ponta, a mais avançada; mas como a única que existe. Logo em seguida, vamos ver como essa ideia se generaliza na sociedade, tornando-se parte do senso comum. E como a universidade internaliza essa ideia que é, em nosso entender, equivocada.

\section{O que faz a TC ser diferente da TS?}

- A TC é funcional para a empresa privada que, no capitalismo, é a responsável por "transformar" conhecimento em bens e serviços;

- Os governos dos países centrais apoiam seu desenvolvimento;

- As organizações e os profissionais que a concebem estão imersos no ambiente social e político que a legitima e demanda;

- Porque trazem consigo seus valores e, por isso, reproduzem-no.

A organização de profissionais que concebem a TC está imersa num ambiente político que a legitima e demanda. Porque trazem incorporados seus valores, reproduzem essa tecnologia. Aprendemos na escola de engenharia que, por exemplo, quanto maior a escala de um sistema tecnológico (ou, mais simplesmente, de uma tecnologia), mais eficiente ela será. $\mathrm{O}$ engenheiro, como também, em geral, os cientistas, é treinado, condicionado, a reproduzir esse padrão de expansão da fronteira 
do conhecimento. Quer dizer, expandimos a fronteira do conhecimento científico e tecnológico de acordo com essa visão convencional, com essa estratégia materialista (como diz: Lacey, 1999) ou capitalista (como dá a entender: Feenberg, 2002), da pesquisa em C\&T. Portanto, o problema não é apenas de organização do processo de trabalho, como supõe a maior parte dos autores que abordam essa questão a partir da perspectiva da economia solidária e da autogestão. Mas é da tecnologia lato sensu e, mais do que isso, da forma como se faz e se concebe a ciência ${ }^{3}$.

Chamo a atenção para o fato de que essa ideia é bastante diferente daquela que até agora se lê nos textos sobre o tema que nos ocupa. Esses textos praticamente reduzem o problema à forma de organização do processo de trabalho que, num empreendimento autogestionário, tem de ser transformada em autogestionária. O problema parece ser muito mais grave. Não é só a maneira como se organiza o trabalho (orgware), mas o substrato tecnológico (hardware e software) e o próprio substrato científico que de alguma maneira produzem a tecnologia que vai ser utilizada na empresa, o que precisa ser transformado. Não basta que o empreendimento seja de cooperados e nem que adote a autogestão. É necessário que disponha de TS.

\section{Será que a universidade tem condições de gerar TS a partir da TC?}

Essa é uma pergunta que decorre daquela primeira colocação que fizemos, ou seja, da hipótese que adotamos, ao criar uma incubadora de cooperativas numa universidade, de que a universidade tem condições de aproximar essas duas vertentes tecnológicas.

Para responder à pergunta proposta no subtítulo, é necessário fazer outras três.

A primeira é: como se dá o desenvolvimento de C\&T (e poderíamos agregar, de acordo com autores marxistas não ortodoxos contemporâneos, no capitalismo)?

A segunda: como a universidade percebe esse desenvolvimento?

Finalmente: como a universidade se organiza para desenvolver conhecimento?

Vou mostrar como entendo o processo de desenvolvimento científico e tecnológico. Em seguida, vou apresentar minha visão a respeito de como a universidade entende esse processo. Finalmente, mostrando

3 Faço um tratamento detalhado do tema em Dagnino (2002a). 
como a universidade se organiza para desenvolver conhecimento, vou sugerir que essa forma de organização tende a ser um obstáculo para a geração de TS.

O desenvolvimento de C\&T, ou de conhecimento científico e tecnológico, reflete os padrões sociais, políticos, econômicos e ecológicos da sociedade em que esse desenvolvimento tem lugar. Isso pode ser aceito por muitos, sobretudo os que já pensaram de maneira não preconceituosa sobre o assunto. Ou leram e aceitam a ideia da construção social da C\&T, principalmente a versão referente à tecnologia defendida por autores como Hughes (2001), Bijker (1995) e Feenberg (2002).

A ideia da ciência como um objeto construído, entretanto, não é aceita na instituição universitária. A grande maioria dos professores da universidade, sejam de direita ou de esquerda, entende a ciência como livre de valores, como algo neutro e intrinsecamente positivo.

Isso em parte se deve ao fato de que foi o marxismo um dos responsáveis pela fundação da ideia do determinismo tecnológico, que é exatamente oposta à ideia de que é o contexto social, econômico e político que determina o tipo de conhecimento científico e tecnológico gerado. Em sua versão mais ortodoxa, tradicional, aquela que de alguma forma orientou as experiências do socialismo real, considerava o desenvolvimento da tecnologia (das "forças produtivas") algo inexorável, contínuo e linear.

Quando se estuda a história da tecnologia, a história da ciência, vê-se que determinados tipos de conhecimento avançaram num ritmo muito mais elevado do que outros; que o desenvolvimento de C\&T parece ser enviesado por padrões exógenos ao campo tecnológico e científico; que, ao longo do tempo, sua trajetória parece estar condicionada pelo interesse de determinados atores centrais, do ponto de vista do poder econômico, político etc. Talvez o exemplo mais óbvio seja o da tecnologia militar. $\mathrm{O}$ fato de que na ex-União Soviética essa tecnologia teve enorme expansão, a ponto de se igualar à do Ocidente, só pode ser explicado pelo interesse de seus governantes.

Essa ideia de que o desenvolvimento do conhecimento é desbalanceado e enviesado por interesses políticos e econômicos é importante para entender a TC. Isso porque tudo se passa como se esse desenvolvimento, entendido por um momento como um ente animado, só fizesse perguntas que consegue resolver (que são funcionais) no âmbito das relações sociais em que ocorre. A ciência não se pergunta nada que não "caiba" dentro dos limites de "sua" sociedade. A ciência, na verdade, não se coloca problemas em função da curiosidade do cientista por meio de 
um contato com a natureza (individual, não determinado pelas relações sociais, pelos interesses dominantes, pelas culturas institucionais em que se verifica esse contato etc.).

Tal noção, que aponta para uma característica da ciência necessária para entender nosso problema, é aceita por pouca gente. De fato, a visão da ciência que estou criticando, apesar de um tanto idílica e ingênua, é a dominante.

A maioria considera que a ciência não tem fronteiras, que é universal, que é a mesma, e deve ser a mesma, em qualquer parte do mundo. Esse argumento parte da constatação de que o Homem e a Natureza são os mesmos em todo o planeta e que a ciência é o resultado da curiosidade inerente do primeiro, que por meio de um método tido como infalível explora solitária e continuamente a segunda - perfeita e intrinsecamente verdadeira - desvelando seus segredos, sua verdade. O tempo seria a única variável na equação que explicaria o avanço da ciência: ele só dependeria do "escoamento" linear do tempo. Se a Ciência avança sempre, contínua, linear e inexoravelmente, seguindo um caminho próprio, e busca a verdade que está na Natureza, perfeita, qualquer dificuldade dos cientistas para entender e dominar a Natureza seria sanada com o passar do tempo.

Nossa visão é a de que a ciência reforça "sua" sociedade e tende a inibir a mudança social. Ou seja, a ciência e a tecnologia produzidas sob a égide da formação social capitalista tendem a inibir uma mudança que contrarie suas regras de funcionamento, que debilite a acumulação do capital, que aponte para uma forma de organização do processo de trabalho e da vida em sociedade diferente.

\section{Como a universidade parece entender esse desenvolvimento?}

Minha percepção é que a universidade tem uma visão de ciência muito semelhante àquela que há pouco critiquei. Ela percebe a ciência como tendo um motor de crescimento que guiaria seu desenvolvimento de acordo com leis próprias, definidas endogenamente. Para que esse motor funcionasse bem, seria necessário que se mantivesse isolado em relação à sociedade. Essa seria a única forma pela qual a ciência poderia se desenvolver de modo verdadeiro e eficaz. Vocês, pelo menos os mais jovens, devem estar pensando: "Puxa, mas existe gente assim?”. Leiam com atenção o que aparece na mídia sobre C\&T. Saiam por aí, pelo campus, conversem com seus colegas e professores, e vejam como a maior parte deles pensa dessa forma. 
É possível entender essa visão a respeito de como seria a trajetória através da qual a ciência se desenvolveria como darwinista. Segundo ela, a tecnologia, que nada mais é do que a ciência aplicada, por estar baseada num conhecimento cada vez mais verdadeiro, melhor, seria também cada vez mais eficiente. Isto é, da mesma forma que a ciência busca a verdade, a tecnologia busca a eficiência. De novo, a única variável desse modelo é o tempo. Assim, a última tecnologia (baseada na última descoberta científica) seria a melhor, e todas as outras seriam atrasadas, obsoletas, não valeriam nada. E aquela, por ser a melhor, vai eliminar todas as outras. E quem não se apressasse a utilizá-la estaria condenado ao atraso, não importando os impactos nocivos de qualquer ordem que ela poderia determinar nas sociedades que a adotam. É nessa visão mecanicista, linear, determinista e acrítica que está fundamentado o conceito de "tecnologia de ponta", de "alta tecnologia", que muitos endeusam sem entender o que está por trás.

A ideia de que uma tecnologia tem "ponta" e que outras são "rombudas", de que algumas são altas e outras baixas, busca, na realidade, substituir a noção de que algumas tecnologias são adequadas para determinados fins, e não para outros, e dificultar a percepção de que algumas são funcionais para a reprodução do capital, mesmo que em detrimento de valores morais, ambientais etc. Mas essa concepção ideologizada do fenômeno científico e tecnológico, como tantas outras presentes no cotidiano, é hegemônica e, por isso, muito dificil de contestar.

A universidade, então, entende o desenvolvimento de C\&T como sendo neutro, não influenciado pelo contexto social. Tal neutralidade pode atuar de forma passiva, sem nenhum impacto enviesado na manutenção ou fortalecimento do poder de algum ator social presente no contexto em que é gerada, ou ativa, determinando por meio de seu impacto a forma que a sociedade assumirá ${ }^{4}$.

Metaforizando a partir dos desenhos animados, a ciência seria uma espada. Se Peter Pan conseguir pegar do chão a espada do Capitão Gancho, poderá matá-lo, pois a espada (como seria a ciência) é neutra: serve aos interesses de quem a estiver manejando. Levando essa imagem à frente, eu diria que a ciência é muito mais parecida com uma vassoura de bruxa. A vassoura de bruxa só voa com "sua" bruxa. Se alguém que não ela tentar montar na vassoura, esta derruba o desavisado que pensou que ela era "neutra".

$\mathrm{Na}$ história, vamos encontrar situações que se assemelham a essa caricatura. A C\&T gerada no capitalismo e importada pela União Soviética

4 Faço um tratamento detalhado do tema em Dagnino (2002b). 
dos anos 1920 não pôde ser usada com sucesso para ajudar a construir o socialismo nascente. Parece que, ao tentar fazer com que funcionasse num contexto marcado por relações técnicas e sociais de produção, esqueceu-se de que precisava, para tanto, de uma forma de organização do trabalho capitalista, com patrão, gerente e tudo o mais. Sem aprofundar a questão, vale lembrar autores marxistas contemporâneos críticos do socialismo real que entendem a degenerescência burocrática do Estado soviético como resultado da introdução de forças produtivas capitalistas numa sociedade já em processo de trânsito ao socialismo, com os meios de produção na mão do Estado sem assalariados. Ou seja, esse conflito entre forças produtivas capitalistas e relações sociais de produção terminou impondo a criação de um sucedâneo do capitalista - o gerente - que já não podia existir. Assim, como a tecnologia demandava a figura do gerente, em função de suas características de segmentação, hierarquização e controle, criou-se o burocrata. Esse burocrata, pelo controle que exercia ao operar a tecnologia capitalista no processo de produção na fábrica, terminou reproduzindo no âmbito maior da sociedade uma diferenciação social semelhante àquela que existia no capitalismo e inviabilizando a transição para o socialismo.

Numa outra visão, a neutralidade seria ativa, ou seja, a C\&T determinaria a dinâmica socioeconômica. É a visão que mais se aproxima do determinismo marxista contida na célebre frase de Marx de que o surgimento do capitalismo teria sido uma consequência da introdução da máquina a vapor, da mesma forma com que o feudalismo teria sido viabilizado pelo estribo e pelo arado, conforme historiadores identificados com a corrente determinista sustentam. Como se o desenvolvimento das forças produtivas fosse o responsável pela sucessão das formas de organização da sociedade, pela sucessão dos modos de produção.

Como a universidade se organiza para desenvolver conhecimento? Como é que a universidade faz pesquisa? Ela se orienta por uma pretensa cadeia linear de inovação - cadeia que se inicia com a pesquisa básica, depois com a aplicada, depois o desenvolvimento tecnológico, depois o econômico e o social, e aí vamos todos para o céu! ${ }^{5}$

Tudo depende da pesquisa básica. Se tivermos boa pesquisa básica, de excelência, como se costuma dizer, se formarmos recursos humanos de qualidade, desencadearemos um processo autossustentado que nos levaria ao bem-estar da sociedade. De novo, essa visão, assim apresentada, deve arrancar de muitos de vocês uma interrogação: "Meu Deus, será que tem gente que pensa assim?”. Tem, e é maioria.

5 Faço um tratamento detalhado do tema em Dagnino (2003a, p. 267-308). 
A concentração do esforço no lado da oferta, para tornar a universidade capaz de oferecer conhecimento à sociedade, é vista pela comunidade de pesquisa como sua única responsabilidade. Se a sociedade utiliza ou não esse conhecimento, não é entendido como um problema seu. Se ela não é capaz de absorvê-lo para produzir mais e melhor, se os empresários, por não terem uma "cultura da inovação", não demandam o que é produzido na universidade, isso não é visto como um problema do tipo de conhecimento que é oferecido. Não é um problema do modo como a agenda de pesquisa é formulada. Afinal, só existe uma maneira de fazer ciência de qualidade. E só um modelo, o ofertista-linear, para organizar a atividade de pesquisa.

Se a sociedade não utiliza o conhecimento produzido na universidade, o problema é da sociedade. Não é a universidade que tem de produzir um conhecimento que seja do interesse da sociedade, que, ao fim e ao cabo, é quem a sustenta. A comunidade de pesquisa, de forma tautológica, pensa o contrário: para resolver esse problema da sociedade, é necessário que ela dê mais valor à ciência. Para que isso aconteça, a universidade precisa oferecer mais conhecimento à sociedade. A universidade tem de fazer uma cruzada para converter a sociedade, para ensiná-la que ciência é uma coisa positiva, é uma coisa boa, é uma coisa que deve ser valorizada.

Então, condicionada pelos problemas estruturais de nossa condição periférica, e focalizada na qualidade, na pesquisa de ponta realizada nos países centrais, a universidade busca emular um padrão de fazer ciência que pouco tem a ver com nossa realidade. E tenta legitimar-se não com nossa sociedade, com nossas unidades produtivas, com nossa floresta, com nossos minérios, como ocorre nos países avançados. Ao contrário, busca identificar-se, legitimar-se, com seus pares no exterior. Quanto mais publicar nos journals da moda, reconhecidos pelo Science Citation Index, e conformar-se ao mainstream da pesquisa dos países avançados, melhor para nossa comunidade de pesquisa. Mais: ela será reconhecida por nossos pares no exterior e, ao menos até agora, por nossa própria sociedade.

Nossa comunidade de pesquisa decidiu que carreira acadêmica deve depender de onde os pesquisadores publicam seus papers: publicado no exterior vale X, publicado no Brasil vale Y. Qualquer ator social - e a comunidade de pesquisa é um ator social - tem interesses, vai orientar a política científica e tecnológica do país, o quanto puder, para atender a seus interesses. 
A universidade, como outras instituições, organiza-se baseando suas decisões na opinião, no faro, no prestígio e no poder de seus líderes e suas redes invisíveis. Por que se faz tal pesquisa e não outra? Por que se dá tal tipo de aula e não outro? Ora, porque alguém disse que tem de ser assim. Mas baseado em quê? Em argumentos racionais? Não, baseado em faro, em prestígio. Na universidade, o poder de quem decide é construído a partir de prestígio acadêmico, o que significa estrita observação desse modo de organização e daquelas regras subjacentes às quais se fez referência.

Em outras palavras, o professor pesquisa, pesquisa, pesquisa, orienta, orienta, orienta, publica, publica, publica e, a partir de um determinado momento, em função do prestígio acadêmico que granjeou, passa a ser um chefe de departamento, um diretor de unidade, um reitor etc. Esse mecanismo de acumulação de poder, baseado no prestígio, não tem nada a ver com algo racional, com uma capacidade técnica para decidir sobre qual tipo de atividade de pesquisa e docência é mais adequado para a sociedade.

A comunidade de pesquisa considera que esse mecanismo garante trajetórias ótimas contra a contaminação não científica, e o que a universidade mais teme é a contaminação não científica. Aqui, no território da ciência, busca-se a verdade. Isso torna desnecessário um processo de tomada de decisão racional. A ideia de que a liberdade acadêmica e a qualidade são suficientes para pautar o desenvolvimento da universidade costuma traduzir-se na recomendação de que planejar é pior do que não planejar. A falta de confiança no planejamento leva a que a universidade não estabeleça uma política de pesquisa, não discuta o profissional que forma. E, em consequência, corre o risco de formar gente para o passado, não para o presente e muito menos para o futuro.

A política de pesquisa é formulada por default, ela não é programada - é o resultado de um conjunto de projetos amorfo, mas sempre aderente às características da TC. Não há uma agenda de pesquisa, no sentido estrito da palavra; há uma decisão por omissão ${ }^{6}$.

Resumindo: a universidade reforça, de maneira sutil, aparentemente natural, enraizada no mito da neutralidade da ciência e em função do contexto socioeconômico que o engendra, a TC. Bom, se parássemos aqui, poderíamos ir embora para casa: essa coisa de incubadora de cooperativas não vai dar certo mesmo. Não tem jeito,

6 Faço um tratamento detalhado do tema em Dagnino; Gomes (2003, p. 159-187). 
está tudo ao contrário. A ciência vai no sentido contrário, a universidade a percebe de uma forma equivocada, organiza-se de uma forma que reforça a TC...

\section{Será que é possível gerar a TS a partir da TC?}

Como se dá o desenvolvimento de C\&T?

- Reflete os padrões sociais, políticos, econômicos e ecológicos da sociedade em que é desenvolvida;

- É desbalanceado e enviesado por esses padrões;

- Só faz perguntas que consegue resolver dentro dos limites desta sociedade;

- Reforça "sua” sociedade e inibe a mudança social.

Como a comunidade de pesquisa percebe esse desenvolvimento?

- Como tendo um "motor de crescimento" endógeno, guiando a C\&T num caminho; linear, contínuo, universal, "darwinista” e inexorável;

\section{Vamos ver o que pode ser feito}

Como começar? Acho que é fazendo isso que estamos fazendo aqui. Questionar essa maneira de organizar a pesquisa na universidade é um primeiro e necessário passo. Claro que não podemos parar aí. Não se pode só criticar ${ }^{7}$.

Temos de gerar uma nova cultura institucional que seja favorável à TS. Uma cultura institucional que viabilize uma agenda, de pesquisa e de formação de recursos humanos, coerente com a IS, a economia solidária, coerente com a TS, alargando seu nicho, no interior do conjunto de projetos que diferentes atores sociais impulsionam de forma aderente à TC.

Dado que nossa política de pesquisa, nossa agenda de pesquisa, é, de fato, uma lista de projetos - aquele conjunto de projetos amorfo a que me referi - não parece tão dificil introduzir ali uma cunha de racionalidade $^{8}$. Ao criticar a maneira como essa agenda é conformada, será

7 Faço um tratamento detalhado do tema em Dagnino (2003b, p. 35-55).

8 Em Dagnino et al. (2002), apresenta-se um conjunto de metodologias que poderiam ser usadas para tornar mais racional o processo de conformação da agenda de pesquisa de universidades e instituições de pesquisa. 
possível explicitar a conveniência de que ela contemple o interesse de outros atores sociais, daqueles que podem alavancar a mudança social que interessa às cooperativas, aos excluídos.

Hoje, o movimento docente de esquerda denuncia que o neoliberalismo está desmantelando a universidade. Mas continua fazendo tudo aquilo que o neoliberalismo quer que a gente faça. Parece que não existe esquerda nem direita, porque o professor de ultraesquerda e o professor de ultradireita fazem a mesma pesquisa, dão a mesma aula9 . Então, que diabos! Espera-se que milagres aconteçam?

As universidades federais ficaram paradas dois meses. A Unam, no México, ficou em greve por um ano. Quem na sociedade, que força social, levantou-se para dizer: "Ô, governo, dá um jeito nisso! Precisamos da universidade!"?

Imagine nos EUA, se Berkeley ou Stanford ficassem paradas uma semana. No outro dia, estariam as multinacionais, as grandes empresas, a sociedade em geral, batendo na porta, "Ô, governo, precisamos desse laboratório. Os pesquisadores que estão adquirindo conhecimento aqui são importantes para nós!”.

Nossa universidade é disfuncional. Ela não serve nem para a classe dominante nem para a classe dominada - é uma universidade que está no limbo. E a esquerda universitária continua sem buscar alianças, no interior da sociedade, que possam defender a universidade. Até por uma questão bem corporativa e pragmática, seria bom perguntar: quem vai nos defender do neoliberalismo? Vai ser o grande capital multinacional? Vai ser o grande capital nacional em processo de extinção? Ou será que vão ser outros os aliados? Se vão ser outros, quem são? Onde estão?

E aí voltam as questões que estamos aqui discutindo: a economia solidária, os empreendimentos autogestionários. Parece-me que essa coisa que estamos tentando fazer é muito mais importante do que vislumbramos à primeira vista. Os desafios que esses conceitos apresentam à nossa relação com o conhecimento (que é a coisa mais preciosa e mais humana que o Homem possui) são muito grandes, muito significativos. Cabe a nós recolher esses desafios e tentar fazer com que façam parte do dia a dia, da pesquisa, do ensino, enfim, daquilo que fazemos aqui.

9 Em Dagnino, Gomes, Costa, Higa e Thomas (2003, p. 95-108), esboçam-se ideias acerca do que poderia ser um comportamento dos professores e pesquisadores de esquerda mais coerente com sua ideologia. 


\section{Referências}

BIJKER, W. Of bicycles, bakelites, and bulbs: toward a theory of sociotechnical change. Cambridge: Massachusetts: Londres, 1995.

DAGNINO, R. Em direção a uma estratégia para a redução da pobreza: a economia solidária e a adequação sociotécnica. In: ORGANIZAÇÃO DOS ESTADOS IBERO-AMERICANOS PARA A EDUCAÇÃO, A CIÊNCIA E A CULTURA. Sala de Lectura CTS+I de la OEI. 2002a. Disponível em: <http://www.campus-oei.org/salactsi/index.html>.

Enfoques sobre a relação ciência, tecnologia e sociedade: neutralidade e determinismo. In: ORGANIZAÇÃO DOS ESTADOS IBEROAMERICANOS PARA A EDUCAÇÃO, A CIÊNCIA E A CULTURA. Sala de Lectura CTS+I de la OEI. 2002b. Disponível em: <http://www. campusoei.org/salactsi/index.html>.

A relação universidade-empresa no Brasil e o "argumento da hélice tripla”. Revista Brasileira de Inovação, Rio de Janeiro, Finep, v. 2, n. 2, p. 267-308, jul./dez. 2003a.

Conferencia inaugural. In: KROTCH, P. (comp.) Las miradas de la universidad. Buenos Aires: Al Margen, 2003b.

A relação pesquisa-produção: em busca de um enfoque alternativo. In: SANTOS, L. et al. Ciência, tecnologia e sociedade: o desafio da interação. Londrina: Iapar, 2004.

DAGNINO, R. et al. Gestão estratégica da inovação: metodologias para análise e implementação. Taubaté: Cabral Universitária, 2002.

DAGNINO, R.; GOMES, E. O processo decisório na universidade pública brasileira: uma visão de análise de política. In: SOBRINHO, D. J.; RISTOFF, I. Dilvo. Avaliação e compromisso público. Campinas: Insular, 2003.

DAGNINO, R.; GOMES, E.; COSTA, G.; HIGA, W.; THOMAS, H. Por uma política de ciência e tecnologia de esquerda. Alternativas. Série Espácios Pedagógicos, v. 8, n. 23, p. 95-108, 2003.

FEENBERG, A. Transforming technology. Oxford: Oxford University Press, 2002.

HUGHES, T. Technological moment. In: SMITH, M. R.; MARX, L. (Eds.) Does technology drive history? Cambridge: The MIT Press, 2001. LACEY, $\mathrm{H}$. Is science value-free? Values and scientific understanding. Londres: Routledge, 1999. 